\title{
Desempenho de frangos de corte oriundos de matrizes de corte submetidas a dietas contendo aflatoxinas e glucomananos esterificados como adsorvente
}

\author{
Alexandre Pires Rosa ${ }^{1}$, Rodrigo Uttpatel ${ }^{2}$, Janio Morais Santurio ${ }^{3}$, Anelcir Scher ${ }^{2}$, Vinicius \\ Duarte $^{4}$, Camila Borba Santos ${ }^{2}$, Lenise Schröder Boemo ${ }^{2}$, Juliana Forgiarini ${ }^{5}$
}

\footnotetext{
1 Departamento de Zootecnia, Laboratório de Avicultura (LAVIC), UFSM, Santa Maria, RS, Brasil.

2 Programa de Pós-graduação em Zootecnia, UFSM, Santa Maria, RS, Brasil.

${ }^{3}$ Departamento de Microbiologia, Laboratório de Pesquisas Micológicas (LAPEMI), UFSM, Santa Maria, RS, Brasil.

${ }^{4}$ Curso de Medicina Veterinária, UFSM, Santa Maria, RS, Brasil.

${ }^{5}$ Curso de Zootecnia, UFSM, Santa Maria, RS, Brasil.
}

RESUMO - Avaliou-se o desempenho da progênie de matrizes de corte que consumiram aflatoxinas e glucomananos esterificados como adsorvente por quatro ou oito semanas. Foram conduzidos dois experimentos no período de 1 a 21 dias de idade. Em cada estudo foram utilizados 160 machos de 1 dia provenientes de matrizes alimentadas com dietas contendo aflatoxinas e adsorvente. Em ambos os ensaios, foi adotado um delineamento experimental inteiramente casualizado para avaliação de cinco dietas (tratamentos), cada uma avaliada com quatro repetições de oito aves. Nas dietas fornecidas às matrizes, as aflatoxinas foram adicionadas nos níveis $0 ; 0,500$; ou $0,750 \mathrm{mg} / \mathrm{kg}$ de ração em combinação ou não a $0,10 \%$ de adsorvente. Os dois ensaios com frangos de corte foram conduzidos em baterias instaladas em unidade experimental climatizada, onde os pintos receberam uma dieta comprovadamente isenta de aflatoxinas durante todo o período experimental. Os parâmetros avaliados foram: peso corporal, ganho de peso, conversão alimentar pelo ganho de peso, proteínas plasmáticas totais, albumina sérica e pesos de fígado e bursa de Fabrícius ao primeiro dia de idade. A adição de até 0,750 mg aflatoxinas/kg e adsorvente durante oito semanas na dieta de matrizes de corte não influencia o desempenho zootécnico nem os parâmetros sanguíneos da progênie das matrizes.

Palavras-chave: glucomananos esterificados, micotoxinas, parâmetros sanguíneos, peso do pintinho, progênie

\section{Performance of broilers derived from breeder hens fed with diets containing aflatoxins and esterified glucomannan as adsorbent}

\begin{abstract}
The performance of the progeny from breeders hens fed diets containing aflatoxins and esterified glucomannans as a mycotoxins adsorbent during four and eight weeks was evaluated. Two experiments were carried out with broiler chickens from 1 to 21 days of age. In each study, one hundred and sixty 1-day old male chicks from broiler breeders fed diets with aflatoxins and mycotoxins adsorbent were used. The chicks were allocated in a completely randomized experimental design with five treatments and four replicates of eight birds each. In the diets supplied to the breeder chickens, aflatoxins were added at levels of $0,0.500$, or $0.750 \mathrm{mg} / \mathrm{kg}$ of the diet with or without $0.10 \%$ adsorbent. The two experiments were conducted in batteries installed in an environmental experimental controlled unit, where chicks received an aflatoxinfree diet during the entire trial period. The parameters studded were: body weight, weight gain, feed:gain ratio by weight gain, total plasmatic proteins, serum albumin, and liver and bursa weights at the first day of age. The addition of levels of up to $0.750 \mathrm{mg}$ aflatoxins $/ \mathrm{kg}$ and adsorbent in the breeders diets during eight weeks does not affect the performance or blood parameters of the broiler breeder progeny.
\end{abstract}

Key Words: blood parameters, chick weight, esterified glucomannan, mycotoxins, progeny

\section{Introdução}

As aflatoxinas são potentes micotoxinas produzidas por fungos do gênero Aspergillus, e Aspergillus flavus e Aspergillus parasiticus são os de maior relevância para a avicultura (Santurio, 2000).
O consumo de dietas contendo aflatoxinas pode provocar apatia, anorexia com baixa taxa de crescimento, baixa conversão alimentar, decréscimo no ganho de peso, diminuição na produção e no peso de ovos e aumenta a susceptibilidade aos desafios ambientais e microbiológicos, causando ainda elevação na mortalidade (Leeson et al., 1995; 
Miazzo et al., 2000; Oguz et al., 2000; Oguz et al., 2003). A aflatoxicose provoca considerável redução nos níveis de proteínas plasmáticas, influenciando a produção de hemoglobina, o mecanismo de coagulação sanguínea e na síntese de importantes sistemas enzimáticos que, associados ao aumento da fragilidade capilar, provoca hemorragias generalizadas (Hygino da Cruz,1996).

A aflatoxina B1 (AFB1) pode contaminar tanto as gemas quanto as claras. Trucksses et al. (1983) encontraram aflatoxinas B1 e M1 e aflatoxicol nos ovos 24 horas após o início do consumo de ração contaminada. Todavia, enquanto o índice postura é afetado somente 8 dias após o início da intoxicação, a eclodibilidade começa a ser afetada 24 horas após o início do consumo. Qureshi et al. (1998) encontraram altas taxas de mortalidade embrionária tardia em ovos provenientes de aves que consumiram rações contendo 5 e $10 \mathrm{mg} / \mathrm{kg}$ e concluíram que, quanto maior o tempo de exposição à toxina, maiores os efeitos. O sistema imunitário também é afetado pelas aflatoxinas e, entre os efeitos, destaca-se aplasia do timo e da bursa de Fabricius, redução do número e da atividade de células $\mathrm{T}$, redução de componentes humorais, interferon e imunoglobulinas (Pestka \& Bondy, 1990; Pier, 1992).

Estudos com Saccharomyces cerevisiae têm atribuído efeito adsorvente de aflatoxinas ao glucomanano esterificado que é extraído da parede celular da levedura (Aravind et al., 2003). Concentrações de 0,5 e 1,0 g de glucomananos esterificados $/ \mathrm{kg}$ em dietas com diferentes concentrações de aflatoxinas ( 0,05 até $5,0 \mathrm{mg} / \mathrm{kg}$ de dieta) tem a capacidade de reverter total ou parcialmente os efeitos deletérios das aflatoxinas sobre o desempenho zootécnico, os parâmetros hematológicos e a resposta imune de frangos de corte (Raju \& Devegowda, 2000; Aravind et al., 2003).

O objetivo neste estudo foi verificar se a alimentação de matrizes de corte com dietas contendo aflatoxinas e glucomananos esterificados influencia o desempenho da progênie.

\section{Material e Métodos}

O experimento foi conduzido no Laboratório de Avicultura (LAVIC) do Departamento de Zootecnia da Universidade Federal de Santa Maria (UFSM) no período de dezembro de 2005 a fevereiro de 2006 e foi dividido em dois experimentos.

Para avaliar a progênie de matrizes de corte intoxicadas com aflatoxinas, foram selecionadas do plantel do LAVIC 300 fêmeas e 40 machos de matrizes de corte da linhagem
Ross 308 com 60 semanas de idade. As matrizes foram selecionadas segundo o peso corporal e a produção de ovos. As aves foram alojadas em 20 boxes de $7 \mathrm{~m}^{2}$ em uma unidade experimental de $300 \mathrm{~m}^{2}$ e alimentadas e manejadas de acordo com recomendações constantes no manual da linhagem. Da $61^{\mathrm{a}}$ até $68^{\underline{\mathrm{a}}}$ semana, as aves receberam as dietas experimentais, contendo ou não aflatoxinas. Foram realizados dois ensaios: no primeiro, foi avaliado o desempenho da progênie de matrizes que receberam aflatoxinas e adsorventes na dieta durante 4 semanas. No segundo, foi avaliada a progênie de matrizes que receberam aflatoxinas e adsorventes por 8 semanas. Para o primeiro teste, foram incubados ovos produzidos durante a $64^{\mathrm{a}}$ semana de idade das matrizes e, para o segundo, ovos produzidos durante a $68^{\text {a }}$ semana. Os ovos utilizados para as duas incubações foram desinfetados por via gasosa, armazenados em sala com temperatura inferior a $23^{\circ} \mathrm{C}$ por no máximo sete dias e, posteriormente, incubados seguindo os padrões normais de incubação. No 18으 dia, todos os ovos foram transferidos para um nascedouro. No 21a dia, foram selecionados os pintos de primeira (sem anomalias aparentes): os mesmos foram sexados, vacinados contra doença de Marek, pesados e selecionados conforme peso médio.

As aflatoxinas fornecidas às matrizes de corte foram produzidas pelo Laboratório de Pesquisas Micológicas (LAPEMI), pela fermentação de arroz parboilizado pelo fungo Aspergillus parasiticus, linhagem NRRL 2999. As aflatoxinas produzidas e adicionadas às dietas foram AFB1 (86\%), AFB2 (8,5\%), AFG1 (3,8\%) e AFG2 (1,7\%). Como adsorvente de micotoxinas na dieta, foi adicionado glucomanano esterificado, incluído a 0,10\%.

Para a avaliação do desempenho no período de 1 a 21 dias de idade, em cada um dos dois ensaios, foram utilizadas 32 aves, totalizando 160 pintos de corte machos da linhagem Ross 308. No estudo dos parâmetros sanguíneos, do peso de fígado e da bursa de Fabrícius, foram utilizadas 12 aves por tratamento ao primeiro dia de idade.

O delineamento experimental foi o inteiramente casualizado para avaliação de 5 dietas (tratamentos), avaliadas com 4 repetições de 8 machos. As dietas foram formuladas com ou sem aflatoxinas nos níveis de 0,500 e $0,750 \mathrm{mg} / \mathrm{kg}$ de ração em combinação ou não a $0,10 \%$ de adsorvente dieta sem aflatoxinas e adsorvente. Assim, foram obtidas cinco dietas: dieta sem adição de aflatoxina e adsorvente; dieta com 0,500 mg de aflatoxina/ $\mathrm{kg}$, sem adsorvente; $0,500 \mathrm{mg}$ aflatoxinas $/ \mathrm{kg}$ de dieta com $0,10 \%$ de adsorvente; $0,750 \mathrm{mg}$ aflatoxinas $/ \mathrm{kg}$, sem adição de adsorvente; $0,750 \mathrm{mg}$ aflatoxinas/kg de dieta com $0,10 \%$ de adsorvente. 
As aves foram alojadas em baterias, compostas por 20 compartimentos de $0,5 \mathrm{~m}^{2}$ cada, com um comedouro e um bebedouro tipo calha por compartimento. As baterias foram instaladas em sala climatizada, com temperatura e umidade mantidas na zona de conforto para as aves.

Os frangos de corte, em ambos os experimentos, receberam a mesma dieta à base de milho e farelo de soja, comprovadamente isenta de aflatoxinas e adsorventes, durante todo o período experimental. O fornecimento da dieta e da água foi à vontade. O peso corporal, o ganho de peso e a conversão alimentar por ganho de peso dos frangos de corte foram avaliados semanalmente. Os níveis de proteínas plasmáticas totais, albumina sérica e pesos de fígado e Bursa de Fabrícius foram avaliados no primeiro dia. A análise estatística foi realizada pelo programa estatístico SAS (Statistical Analysis System, versão 8.1) e os dados foram submetidos à análise de variância com comparação das médias pelo teste Tukey a 5\% de significância.

\section{Resultados e Discussão}

O peso corporal da progênie após quatro (Tabela 1; Figura 1) oito semanas (Tabela 2) de adição de aflatoxinas e adsorvente à dieta das matrizes não teve qualquer variação significativa em nenhum dos períodos avaliados. Esses resultados estão de acordo com relatos de Howarth \& Wyatt (1976) de que o ganho de peso da progênie, assim como a conversão alimentar, avaliada por duas semanas após a eclosão, não são influenciados significativamente pelo consumo, pelas matrizes de corte, de aflatoxinas no nível de 10 mg/kg de ração. Doerr et al. (1983) alimentaram frangos de corte com dietas contendo aflatoxinas no nível de $0,9 \mathrm{mg} / \mathrm{kg}$ de dieta e não notaram diminuição do peso corporal. Esse efeito somente foi observado quando as aves ingeriram a dieta contendo aflatoxina no nível de 2,7 mg/kg.

Fernandes et al. (2004) verificaram que pintos provenientes de matrizes que consumiram aflatoxinas apresentavam peso corporal inferior ao daqueles oriundos de matrizes alimentadas com dieta sem aflatoxinas aos 7 dias de idade. Contudo, essa diferença não foi observada neste estudo.

A conversão alimentar dos pintos de corte não foi influenciada pela inclusão de aflatoxinas e adsorvente na dieta das matrizes. A viabilidade criatória não sofreu qualquer variação significativa provocada pela inclusão de aflatoxinas na dieta das matrizes, fato que confirma relatos de Howarth \& Wyatt (1976), que também não observaram efeito da adição de aflatoxinas nos níveis de 5 e $10 \mathrm{mg} / \mathrm{kg}$ na dieta de matrizes de corte sobre a mortalidade de frangos.

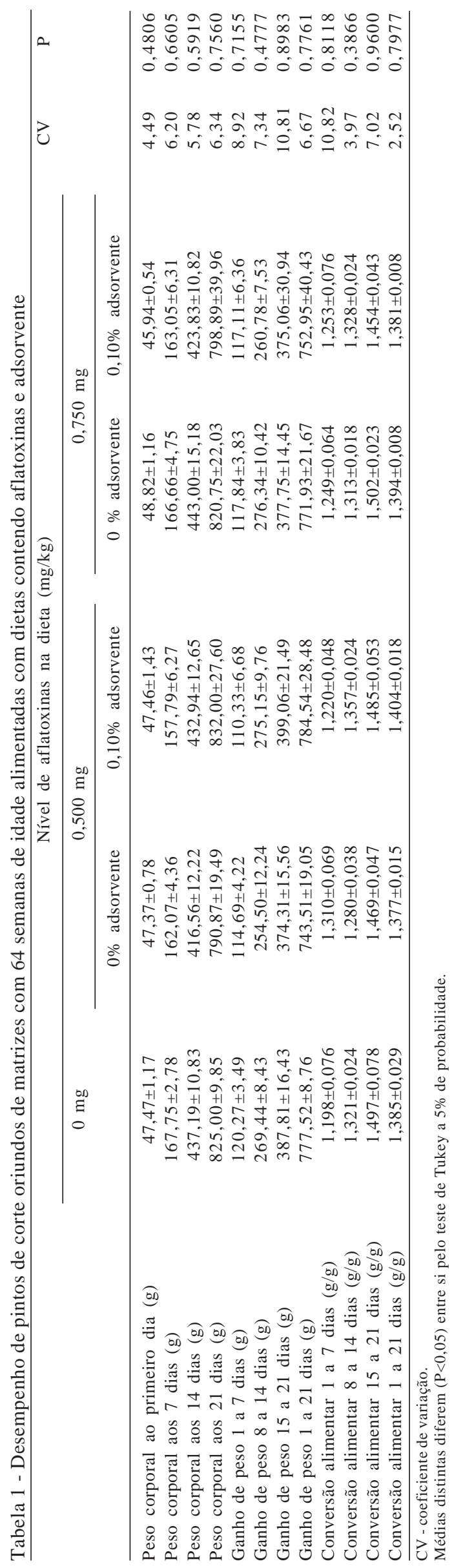

R. Bras. Zootec., v.41, n.2, p.347-352, 2012 

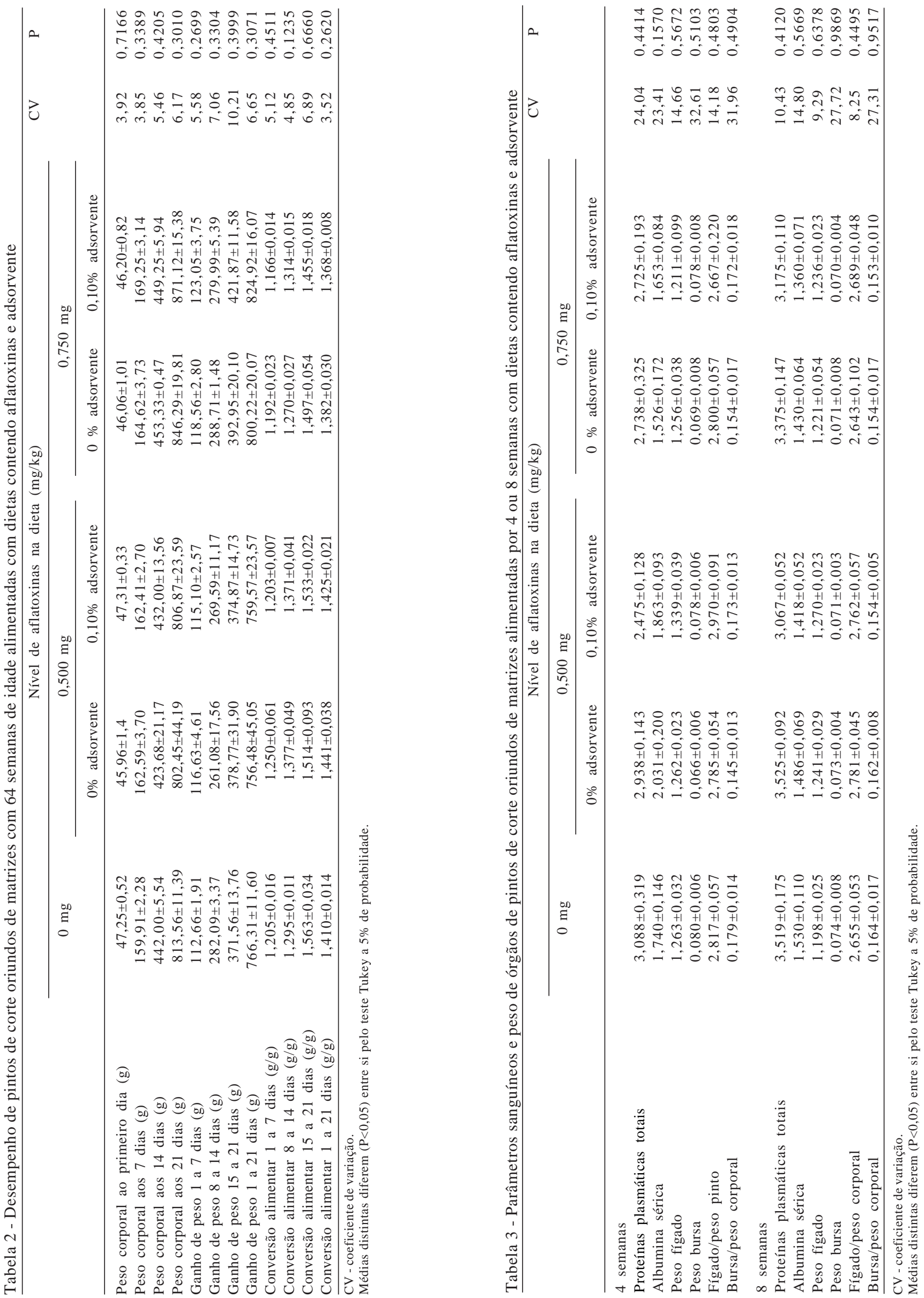


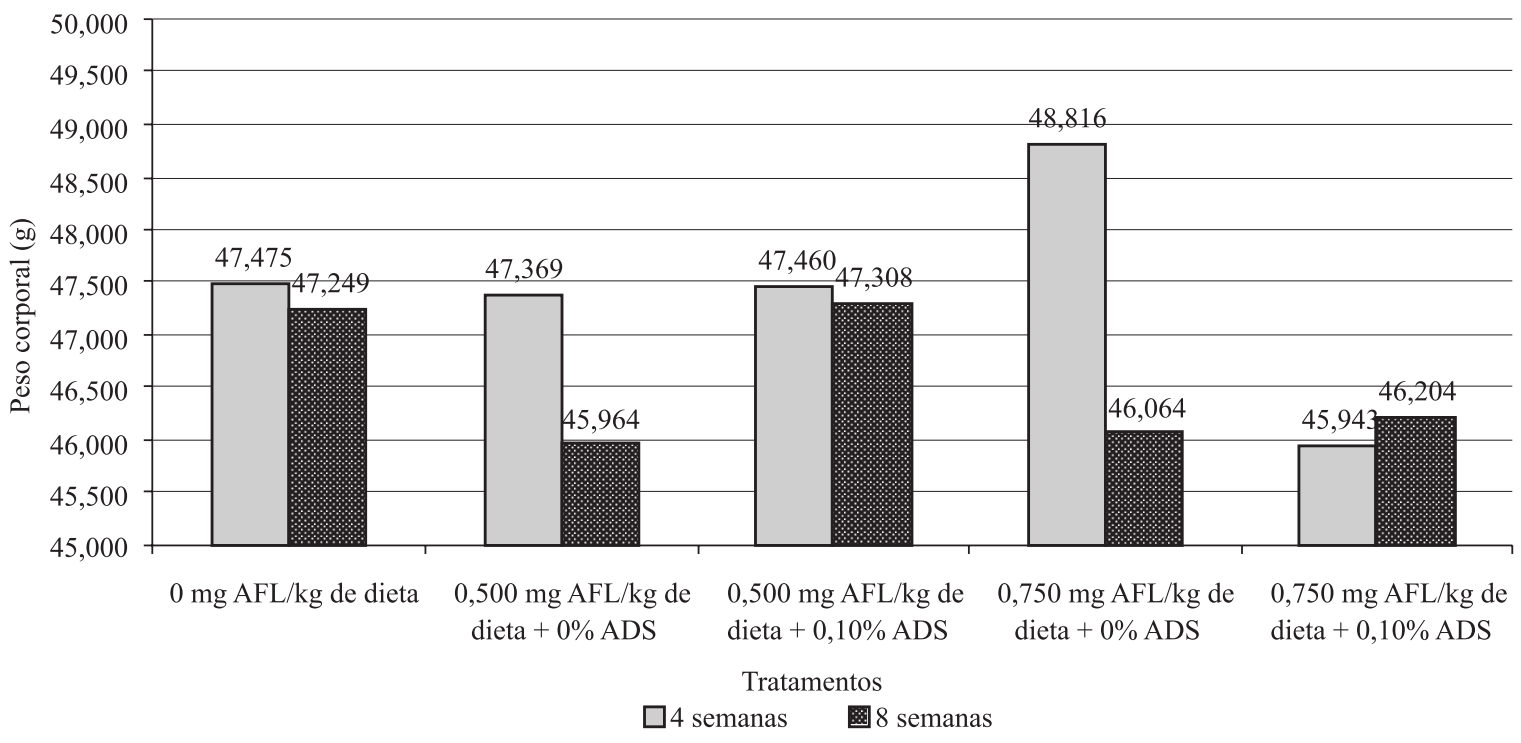

AFL - aflatoxina; ADS - adsorvente

Figura 1 - Comportamento do peso corporal ao primeiro dia de idade de pintos de corte oriundos de matrizes alimentadas por 4 ou 8 semanas com dietas contendo aflatoxinas combinadas ou não com glucomanano esterificado.

Os parâmetros sanguíneos da progênie (Tabela 3) não foram influenciados pelos níveis de aflatoxinas e adsorvente na dieta de matrizes de corte, concordando com resultados obtidos por Huff et al. (1986), que, avaliando três níveis de aflatoxinas (1,25; 2,5 e $5 \mathrm{mg} / \mathrm{kg}$ de dieta), verificaram que os níveis sanguíneos de albumina e proteínas de frangos oriundos de matrizes alimentadas com dietas contendo aflatoxinas no nível de $1,25 \mathrm{mg} / \mathrm{kg}$ foram similares aos de aves do tratamento controle, sem aflatoxinas.

Os pesos do fígado e da bursa de Fabrícius (Tabela 3) dos pintos de 1 dia de idade não foram significativamente influenciados pelos tratamentos. Da mesma forma, Thaxton et al. (1974) não encontraram diferenças significativas no peso de bursa de Fabrícius quando avaliaram a adição de aflatoxinas no nível de $0,625 \mathrm{mg} / \mathrm{kg}$ de dieta. Esses autores observaram, no entanto, redução no peso da bursa de Fabrícius quando alimentaram as aves a dietas contendo aflatoxinas em níveis superiores a 1,25 mg/kg de dieta.

\section{Conclusões}

O consumo durante quatro ou oito semanas de dietas contaminadas com aflatoxinas e adsorventes por matrizes de corte não influencia no desempenho da progênie.

\section{Agradecimentos}

Ao Conselho Nacional de Desenvolvimento Científico e Tecnológico (CNPq), pela concessão de bolsa ao primeiro, quarto e quinto autores. Ao Laboratório de Avicultura (LAVIC) da Universidade Federal de Santa Maria (UFSM), pela infraestrutura para a realização do trabalho.

\section{Referências}

ARAVIND, K.L.; PATIL, V.S.; DEVEGOWDA, G. et al. Efficacy of esterified glucomannan to counteract mycotoxicosis in naturally contaminated feed on performance and serum biochemical, haematological parameters in broilers. Poultry Science, v.82, p.571-576, 2003.

DOERR, J.A.; HUFF, W.E.; WABECK, C.J. et al. Effects of low level chronic aflatoxicosis in broiler chickens. Poultry Science, v.62, n.10, p.1971-1977, 1983.

FERNANDES, A.J. Desempenho produtivo e reprodutivo de matrizes de corte alimentadas com dietas contendo doses crescentes de aflatoxinas. 2004. 65f. Dissertação (Mestrado em Zootecnia) - Programa de Pós-graduação em Zootecnia, Universidade Federal de Santa Maria, Santa Maria, 2004.

HYGINO DA CRUZ, L.C. Micotoxinas: são tão importantes? In: Micotoxinas: perspectiva latino-americana. Seropédica: UFRRJ, 1996. p.1-12.

HOWARTH JUNIOR, B.; WYATT, R.D. Effect of dietary aflatoxin on fertility, hatchability and progeny performance of broiler breeder hens. Applied and Environmental Microbiology, v.31, n.5, p.680-684, 1976.

HUFF, W.E.; KUBENA, L.F.; HARVEY, R.B. et al. Progression of aflatoxicosis in broiler chickens. Poultry Science, v.65, n.10, p.1891-1899, 1986.

LEESON, S.; DIAZ, G.J.; SUMMERS, J.D. Poultry metabolic disorders and mycotoxins. Guelph: University Books, 1995. p.249-280.

MiAZZO, R.; ROSA, C.A.; MAGNOLI, C. et al. Efficacy of synthetic zeolite to reduced the toxicity of aflatoxin in broiler chicks. Poultry Science, v.79, p.1-6, 2000.

OGUZ, H.; KEÇECI, T.; BIRDANE, Y.O. et al. Effect of clinoptilolite on serum biochemical and haematological characters of broiler chickens during experimental aflatoxicosis. Research in Veterinary Science, v.69, p.89-93, 2000. 
OGUZ, H.; HADIMLI, H.H.; KURTOGLU, V. et al. Evaluation of humoral immunity of broilers during chronic aflatoxin (50 and $100 \mathrm{ppb}$ ) and clinoptilolite exposure. Revue de Medécine Vétérinaire, v.154, n.7, p.483-486, 2003.

PESTKA, J.J.; BONDY, G.S. Alteration of immune function following dietary mycotoxin exposure. Canadian Journal of Physiology and Pharmacology, v.68, n.7, p.1009-1016, 1990.

PIER, A.C. Major biological consequences of aflatoxicosis in animal production. Journal of Animal Science, v.70, n.12, p.3964-3967, 1992.

QURESHI, M.A.; BRAKE, J.; HAMILTON, P.B. et al. Dietary exposure of broiler breeders to aflatoxin results in immune dysfunction in progeny chicks. Poultry Science, v.77, p.812-819, 1998.
RAJU, M.V.L.N.; DEVEGOWDA, G. Influence of esterifiedglucomannan on performance and organ morphology, serum biochemistry and hematology in broilers exposed to individual and combined mycotoxicosis (aflatoxin, ochratoxin and T-2 toxin). British Poultry Science, v.41, p.640-650, 2000. SANTURIO, J.M. Micotoxinas e micotoxicoses na avicultura Revista Brasileira de Ciência Avícola, v.2, n.1, p.1-12, 2000.

THAXTON, J.P.; TUNG, H.T.; HAMILTON, P.B. Immunosuppression in chickens by aflatoxina. Poultry Science, v.53, p.721-725, 1974.

TRUCKSSES, M.W.; STOLOFF, L.; YOUNG, K. et al. Aflatoxicol and aflatoxins B1 e M1 in eggs and tissues of laying hens consuming aflatoxin-contaminates feed. Poultry Science, v.62, p.2176-2182, 1983. 